\section{BMJ Open Respiratory Research}

\title{
Early conscious prone positioning in patients with COVID-19 receiving continuous positive airway pressure: a retrospective analysis
}

\author{
Stuart Winearls, ${ }^{1}$ Ema L Swingwood, ${ }^{2,3}$ Charlotte L Hardaker, ${ }^{2}$ Amy M Smith, ${ }^{2}$ \\ Fraser M Easton, ${ }^{1}$ Katherine J Millington, ${ }^{1}$ Rebecca S Hall, ${ }^{2}$ Ann Smith, ${ }^{3}$ \\ Katrina J Curtis ${ }^{1}$
}

To cite: Winearls S, Swingwood EL, Hardaker CL, et al. Early conscious prone positioning in patients with COVID-19 receiving continuous positive airway pressure: a retrospective analysis. BMJ Open Resp Res 2020;7:e000711. doi:10.1136/ bmiresp-2020-000711

SW and ELS contributed equally.

Received 13 July 2020 Revised 17 August 2020 Accepted 20 August 2020

Check for updates

(c) Author(s) (or their employer(s)) 2020. Re-use permitted under CC BY-NC. No commercial re-use. See rights and permissions. Published by BMJ.

${ }^{1}$ Department of Respiratory Medicine, Bristol Royal Infirmary, Bristol, UK ${ }^{2}$ Adult Therapy Services, Bristol Royal Infirmary, Bristol, UK

${ }^{3}$ Faculty of Health and Applied Sciences, University of the West of England Bristol, Bristol, UK

Correspondence to Dr Katrina J Curtis; katrina.curtis@uhbw.nhs.uk

\section{ABSTRACT}

The global pandemic of COVID-19 has challenged the management of hypoxaemic respiratory failure and strained intensive care unit resources. While prone positioning (PP) is an established therapy in mechanically ventilated patients with acute respiratory distress syndrome (ARDS), its role in conscious patients is less well defined. We retrospectively reviewed our experience of implementing early PP in a cohort of 24 patients with acute hypoxaemic respiratory failure due to COVID-19 who required support with continuous positive airway pressure (CPAP). The use of PP alongside CPAP significantly increased both the ROX index and arterial oxygen pressure:fractional inspired oxygen $\left(\mathrm{PaO}_{2}: \mathrm{FiO}_{2}\right)$ ratio from baseline values (ROX index: $7.0 \pm 2.5$ baseline vs $11.4 \pm 3.7$ CPAP+PP, $p<0.0001 ; \mathrm{PaO}_{2}: \mathrm{FiO}$ ratio: $143 \pm 73 \mathrm{~mm} \mathrm{Hg}$ baseline vs $252 \pm 87 \mathrm{~mm} \mathrm{Hg}$ CPAP+PP, $p<0.01$ ), and the changes to both the $\mathrm{ROX}$ index and $\mathrm{PaO}_{2}: \mathrm{FiO}_{2}$ ratio remained significant 1 hour after cessation of proning. The mean duration of PP in the first 24 hours was $8 \pm 5$ hours. Few complications were observed and PP was continued for a mean of $10 \pm 5$ days. From our experience in a dedicated COVID-19 respiratory high care unit, PP alongside CPAP therapy was feasible, tolerated, safe and improved oxygenation. The use of conscious PP in ARDS warrants further investigation in randomised controlled trials.

\section{INTRODUCTION}

The COVID-19 pandemic has challenged the management of hypoxaemic respiratory failure, as limited intensive care capacity is strained by a novel disease with a high mortality and large numbers of patients requiring prolonged periods of invasive ventilation. While early and prolonged prone positioning (PP) reduces mortality in invasively ventilated patients with acute respiratory distress syndrome (ARDS), ${ }^{1}$ its role in conscious patients is uncertain. PP improves the homogeneity of lung aeration through recruitment of dorsal lung segments, reducing ventilation-perfusion mismatch, and ameliorates the high transpulmonary pressure variations and regional hyperinflation that exacerbate lung injury. ${ }^{1}$

Few studies have examined the physiological effects of conscious PP in ARDS, ${ }^{2-5}$ and this strategy has not been widely adopted. Reports have shown improved respiratory parameters with conscious PP in COVID-19 associated ARDS, ${ }^{6-8}$ and two groups have studied its use alongside non-invasive ventilation. ${ }^{78}$ However, the reported duration of PP was short and there remain few studies of its application outside an intensive care setting.

At the onset of the COVID-19 pandemic, we established a designated COVID-19 respiratory high care unit at the Bristol Royal Infirmary. This unit managed patients with ARDS due to COVID-19, both those in whom CPAP was a ceiling of therapy and those who were candidates for invasive ventilation. We adopted a policy of early conscious PP in patients with COVID-19 associated ARDS requiring CPAP and conducted a retrospective review of our experience, reporting the physiological changes, alongside the duration and tolerance of PP.

\section{METHODS}

Twenty-eight patients with ARDS due to severe acute respiratory syndrome coronavirus 2 (SARS-CoV-2), confirmed on nasopharyngeal swab, admitted between 8th April and 31st May 2020 required CPAP and were assessed for PP. CPAP was indicated if arterial oxygen saturations were maintained less than $94 \%$ or there was respiratory distress, despite the delivery of high concentration supplemental oxygen therapy. Four patients were excluded from PP due to contraindications (imminent 
intubation, reduced conscious level, significant immobility or current pressure areas).

Patients received verbal and written information on the rationale and practicalities of $\mathrm{PP}$, and patient positioning was recorded at least hourly. Physiological parameters were recorded immediately prior to CPAP initiation, while on CPAP prior to PP, during PP on CPAP (15 minutes after PP initiation) and 1 hour after PP while on CPAP.

Arterial oxygen saturations $\left(\mathrm{SpO}_{2}\right)$ were measured by pulse oximetry. The arterial oxygen pressure:fractional inspired oxygen $\left(\mathrm{PaO}_{2}: \mathrm{FiO}_{2}\right)$ ratio $^{9}$ and ROX index, a composite measure of oxygenation and work of breathing $\left(\mathrm{ROX}\right.$ index $=\left[\mathrm{SpO}_{2} / \mathrm{FiO}_{2}\right] /$ respiratory rate $),{ }^{10}$ was calculated at each time point. The chest radiograph most recently performed prior to the initiation of CPAP was graded by an independent thoracic radiologist to assess the extent of consolidation. This was combined with the $\mathrm{PaO}_{2}: \mathrm{FiO}_{2}$ index and positive end-expiratory pressure required to maintain adequate oxygenation to calculate the Murray Lung Injury Score. ${ }^{11}$

The duration of PP achieved in the first 24hours, number of consecutive days PP was adopted, nature of the PP (full or semiprone) and any complications were obtained from review of the medical records. Patient outcomes are reported at 28 days post admission. The research and development department of the University Hospitals Bristol and Weston Trust approved the retrospective data collection from electronic observations and case notes, and further analysis of this cohort. As a service evaluation, using routinely collected patient data held in an anonymised database, informed consent and approval of a research ethics committee were not required.

Analysis of variance with post hoc correction for multiple testing was used to compare $\mathrm{ROX}$ and $\mathrm{PaO}_{2}: \mathrm{FiO}_{2}$ indices at each time point, with statistical analysis conducted using GraphPad Prism (GraphPad Software, San Diego, California, USA). A p value $<0.05$ was considered statistically significant.

\section{RESULTS}

The patients' characteristics are summarised in table 1 . All 24 subjects had hypoxaemic respiratory failure and received CPAP to maintain adequate oxygenation, with none requiring bi-level pressure support. Of the 24 subjects, 2 failed to tolerate PP, 1 due to worsening oxygenation and 1 due to pain. PP was initiated a median of 30 (IQR 7-99) hours after the commencement of CPAP, and the mean duration of PP in the first 24 hours was $8 \pm 5$ hours. PP was continued for a mean of $10 \pm 5$ days. No sedation or anxiolytics were required to tolerate PP. Patients required the assistance of one nursing staff member to prone with the exception of one subject with a previous limb amputation. 12 patients adopted a full prone position, and the remaining 10 were semiprone in a lateral position due to discomfort caused by a fully prone position.
Table 1 Baseline characteristics of the patients with COVID-19 ARDS who received CPAP and attempted conscious PP $(n=24)$

\begin{tabular}{|c|c|}
\hline Characteristics & Value \\
\hline Age, years & $62(13)$ \\
\hline Male sex, n (\%) & $15(63)$ \\
\hline \multicolumn{2}{|l|}{ Coexisting conditions, n (\%) } \\
\hline Diabetes & $7(29)$ \\
\hline Hypertension & $13(54)$ \\
\hline Renal failure & $2(8)$ \\
\hline COPD & $0(0)$ \\
\hline Heart failure & $1(4)$ \\
\hline Cancer & $2(8)$ \\
\hline Immunodeficiency, n (\%) & $2(8)$ \\
\hline APACHE II score & $11(5)^{*}$ \\
\hline CFS & $2(1-3)$ \\
\hline ROX index prior to CPAP & $6.8(2.5)$ \\
\hline $\mathrm{PaO}_{2}: \mathrm{FiO}_{2}$ prior to CPAP, $\mathrm{mm} \mathrm{Hg}$ & $112(106-194)$ \\
\hline \multicolumn{2}{|l|}{ ARDS severity classification, $\mathrm{n}(\%)$} \\
\hline$<100$ (severe) & $5(21)$ \\
\hline 100-200 (moderate) & $14(58)$ \\
\hline 200-300 (mild) & $3(13)$ \\
\hline$>300$ & $2(8)$ \\
\hline Murray Lung Injury Score & $2.7(2.7-3.0)$ \\
\hline Maximum PEEP required, $\mathrm{cmH}_{2} \mathrm{O}$ & $12(12-15)$ \\
\hline Maximum $\mathrm{FiO}_{2}$ required & $0.60(0.50-0.70)$ \\
\hline
\end{tabular}

Data are shown as number (\%) for categorical variables and mean (SD) or median (IQR).

*Insufficient data meant the APACHE II score could not be calculated in six patients.

APACHE, Acute Physiology and Chronic Health Evaluation; ARDS, acute respiratory distress syndrome; CFS, Clinical Frailty Score; COPD, chronic obstructive pulmonary disease; CPAP, continuous positive airway pressure; $\mathrm{FiO}_{2}$, fractional inspired oxygen; $\mathrm{PaO}_{2}$, arterial oxygen pressure; PEEP, positive end-expiratory pressure; $\mathrm{PP}$, prone positioning.

There was no significant difference in the measured respiratory rate at each time point (baseline $27 \pm 6$ breaths / min; CPAP $25 \pm 6$ breaths/min; PP on CPAP $24 \pm 6$ breaths/ min; post-PP $25 \pm 6$ breaths $/ \mathrm{min} ; \mathrm{p}=0.24$ ). The mean arterial oxygen saturation increased once CPAP therapy started although was not statistically different from baseline levels (baseline $94 \pm 3 \%$ vs CPAP $95 \% \pm 2 \%$; $\mathrm{p}=0.23$ ). Once PP was adopted on CPAP therapy, the mean arterial oxygen saturation was significantly different from baseline levels (baseline $94 \% \pm 3 \%$ vs PP on CPAP $96 \% \pm 2 \%$; $\mathrm{p}<0.005)$, and this difference was sustained 1 hour after cessation of PP (baseline 94\% $\pm 3 \%$ vs post-PP 96\% $\pm 2 \%$; $\mathrm{p}<0.05)$.

The ROX index at each time point is shown in figure 1 . There was a significant increase in the ROX index only once PP was adopted on CPAP from baseline values (baseline $7.0 \pm 2.5$ vs PP on CPAP 11.4 \pm 3.7 ; p $<0.0001$ ), 


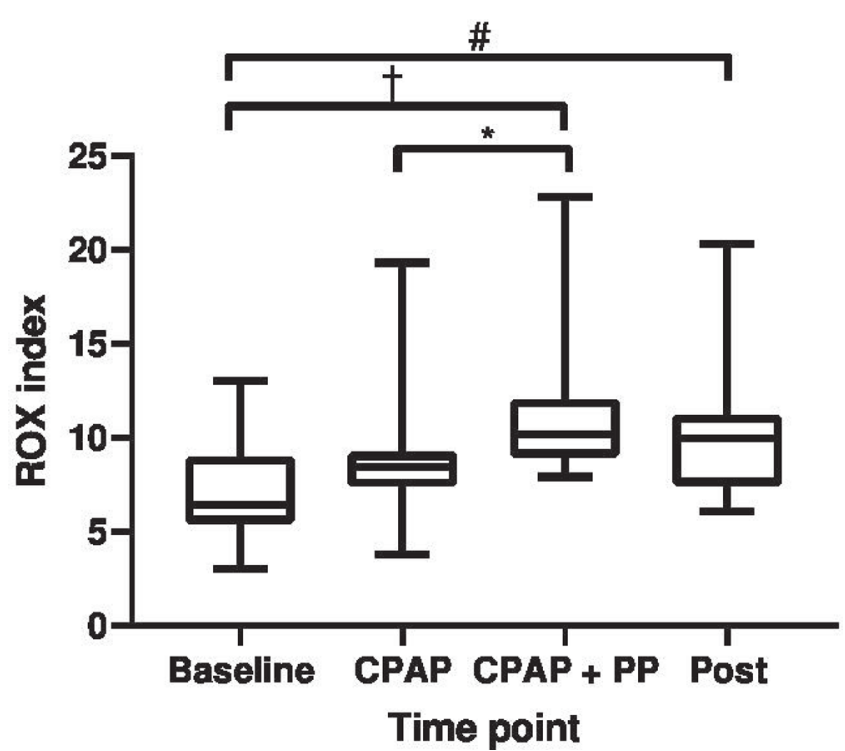

Figure 1 ROX scores prior to continuous positive airway pressure (CPAP) (baseline), following CPAP initiation (CPAP), prone positioning on CPAP (CPAP+PP) and 1 hour after cessation of proning while on CPAP (post). Analysis of variance with correction for multiple testing was used to compare each time point. *Significantly different from CPAP, $\mathrm{p}<0.05$. †Significantly different from baseline, $\mathrm{p}<0.0001$. \#Significantly different from baseline, $p<0.01$.

this difference being non-significant on CPAP therapy alone (baseline 7.0 \pm 2.5 vs CPAP $8.9 \pm 3.2 ; \mathrm{p}=0.31$ ). The increase in the ROX index from baseline was maintained 1 hour after cessation of PP (baseline $7.0 \pm 2.5$ vs post-PP

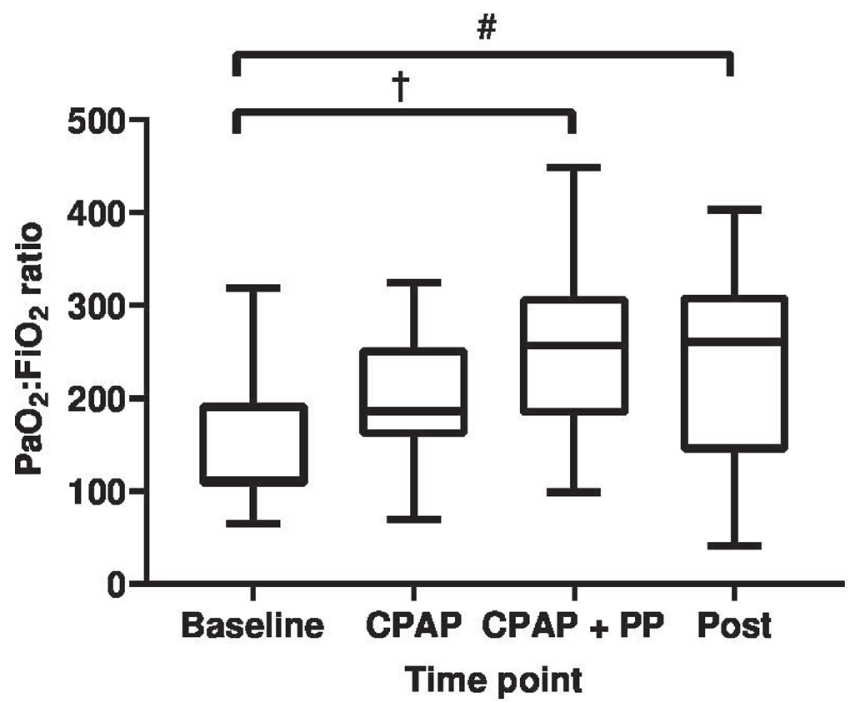

Figure 2 Arterial oxygen pressure:fractional inspired oxygen $\left(\mathrm{PaO}_{2}: \mathrm{FiO}_{2}\right)$ ratios prior to continuous positive airway pressure (CPAP) (baseline), following CPAP initiation (CPAP), prone positioning on CPAP (CPAP+PP) and 1 hour after cessation of proning while on CPAP (post). Analysis of variance with correction for multiple testing was used to compare each time point. †Significantly different from baseline, $p<0.01$. \#Significantly different from baseline, $\mathrm{p}<0.05$.
$10.3 \pm 3.5 ; \mathrm{p}<0.01)$. The use of PP alongside CPAP significantly increased the $\mathrm{PaO}_{2}: \mathrm{FiO}_{2}$ ratio from baseline values (baseline $143 \pm 73 \mathrm{~mm} \mathrm{Hg}$ vs $\mathrm{PP}$ on CPAP $252 \pm 87 \mathrm{~mm}$ $\mathrm{Hg} ; \mathrm{p}<0.01$ ), the difference in the $\mathrm{PaO}_{2}: \mathrm{FiO}_{2}$ ratio being non-significant between baseline and CPAP therapy alone (baseline $143 \pm 73 \mathrm{~mm} \mathrm{Hg}$ vs CPAP $201 \pm 70 \mathrm{~mm} \mathrm{Hg}$; $\mathrm{p}=0.34)$. The increase in the $\mathrm{PaO}_{2}: \mathrm{FiO}_{2}$ ratio remained significant 1 hour after cessation of proning (baseline $143 \pm 73 \mathrm{~mm} \mathrm{Hg}$ vs post-PP $234 \pm 107 \mathrm{~mm} \mathrm{Hg} ; \mathrm{p}<0.05$ ) (figure 2). An improvement in $\mathrm{ROX}$ and $\mathrm{PaO}_{2}: \mathrm{FiO}_{2}$ indices was observed for all ARDS severities. There were no significant differences between the changes from baseline in ROX index or $\mathrm{PaO}_{2}: \mathrm{FiO}_{2}$ ratio between those who adopted full PP versus those who were only able to adopt a semiprone position on CPAP $(\triangle \mathrm{ROX}$ index full PP $5 \pm 5$ vs semiprone $4 \pm 3 ; \mathrm{p}=0.46 ; \Delta \mathrm{PaO}_{2} / \mathrm{FiO}_{2}$ ratio full PP $124 \pm 84 \mathrm{~mm} \mathrm{Hg}$ vs semiprone $90 \pm 89 \mathrm{~mm} \mathrm{Hg}$; $\mathrm{p}=0.38$ ).

Apart from the 2 patients unable to tolerate PP, no complications were recorded. At 28 days post admission, 19 patients had been weaned off CPAP and 18 discharged, with 1 remaining as an inpatient. 1 patient proceeded to invasive ventilation, from the subgroup of 14 patients in whom this was appropriate, and this patient was later discharged from the intensive care unit. 4 patients had died by day 28 postadmission, of these 3 had significant cardiorespiratory comorbidities and Clinical Frailty Scores ranging from 4 to 6 . The remaining patient presented with a new acute haematological malignancy at the time of his presentation with COVID-19 associated ARDS and was assessed alongside an intensive care physician and deemed not suitable for invasive mechanical ventilation.

\section{DISCUSSION}

This retrospective review adds to the growing evidence that conscious PP may have a role in the management of ARDS in the context of COVID-19 infection. It supports previous findings in this group ${ }^{48}$ and does so across a range of ARDS severities and was delivered effectively outside of an intensive care setting.

PP in mechanically ventilated patients with ARDS requires the concomitant use of sedative and frequently neuromuscular blocking agents, with pressure sores and compressive neuropathies being recognised complications. In this retrospective review few complications were noted, even during more prolonged periods of PP than previously reported in conscious patients, ${ }^{578}$ and when this was performed over several consecutive days. Conscious patients were able to adjust their position when prone which likely contributes to the reduced complication rate seen. The use of conscious PP alongside CPAP therapy was both feasible and tolerated in a ward environment with few resource requirements. This contrasts to invasively ventilated patients and the high resource intensity proning this group inherently entails. This has important implications in the management of ARDS when intensive care resources may be overwhelmed by 
demand, as has occurred in many healthcare systems managing COVID-19. While we note that this cohort is likely to be underpowered to detect significant differences due to the position adopted during conscious $\mathrm{PP}$, it is interesting to note that even in those adopting a semiprone position physiological improvements were still observed. Thus, the inability to adopt a full prone position should not deter from attempts to prone.

In spontaneously breathing patients with ARDS patientinduced lung injury is hypothesised to be important in its progression. The ROX index has been validated in patients with ARDS treated with nasal high flow oxygen therapy, ${ }^{10}$ and provides a composite of both oxygenation and work of breathing. The reduction of the ROX index achieved by PP on CPAP may suggest that use of this treatment modality could avoid further disease progression by reducing work of breathing. Further studies to validate the role of the ROX index in patients with ARDS receiving CPAP are required; however, this index may be helpful to describe the ARDS population given that high transpulmonary pressure swings that occur with a high work of breathing is noted to exacerbate the underlying lung injury. ${ }^{1}$

The improvement in respiratory parameters achieved by PP on CPAP provides a potential alternative to increasing the positive end-expiratory pressure, which may be both poorly tolerated in conscious patients and may exacerbate the lung injury through barotrauma. The evidence from invasively ventilated patients with ARDS shows that early, prolonged PP is crucial to its success ${ }^{1}$ and we were able to institute PP early after CPAP commencement and for long periods in conscious patients.

This study has limitations being an uncontrolled, nonrandomised study, with a small sample size that may be prone to bias and no formal proning protocol. However, it adds to a body of evidence that physiological benefits are demonstrated and prospective randomised controlled studies of conscious PP in this group are warranted. Important research questions remain about whether PP can be considered as a 'preventative' rather than 'rescue' therapy in ARDS, delaying or avoiding mechanical ventilation and improving associated morbidity and mortality.

Acknowledgements The authors wish to thank the COVID-19 respiratory high care unit staff and respiratory physiotherapy team in the Bristol Royal Infirmary.
Contributors SW, ELS, FME, KJM and KJC conceived the study idea. Data collection and analysis was performed by SW, ELS, CLH, AMS, FME, KJM, RSH, AS and KJC. All authors provided intellectual interpretation of results and approval of the final manuscript. KJC acts as the guarantor for this manuscript.

Funding The authors have not declared a specific grant for this research from any funding agency in the public, commercial or not-for-profit sectors.

Disclaimer The views expressed in this publication are those of the authors and not necessarily those of the National Health Service or the Department of Health.

Competing interests None declared.

Patient consent for publication Not required.

Provenance and peer review Not commissioned; externally peer reviewed.

Open access This is an open access article distributed in accordance with the Creative Commons Attribution Non Commercial (CC BY-NC 4.0) license, which permits others to distribute, remix, adapt, build upon this work non-commercially, and license their derivative works on different terms, provided the original work is properly cited, appropriate credit is given, any changes made indicated, and the use is non-commercial. See: http://creativecommons.org/licenses/by-nc/4.0/.

\section{REFERENCES}

1 Munshi L, Del Sorbo L, Adhikari NKJ, et al. Prone position for acute respiratory distress syndrome. A systematic review and metaanalysis. Ann Am Thorac Soc 2017;14:S280-8.

2 Valter C, Christensen AM, Tollund C, et al. Response to the prone position in spontaneously breathing patients with hypoxemic respiratory failure. Acta Anaesthesiol Scand 2003;47:416-8.

3 Feltracco P, Serra E, Barbieri S, et al. Non-Invasive ventilation in prone position for refractory hypoxemia after bilateral lung transplantation. Clin Transplant 2009;23:748-50.

4 Scaravilli V, Grasselli G, Castagna L, et al. Prone positioning improves oxygenation in spontaneously breathing nonintubated patients with hypoxemic acute respiratory failure: a retrospective study. J Crit Care 2015;30:1390-4.

5 Ding L, Wang L, Ma W, et al. Efficacy and safety of early prone positioning combined with HFNC or NIV in moderate to severe ARDS: a multi-center prospective cohort study. Crit Care 2020;24:28.

6 Elharrar X, Trigui Y, Dols A-M, et al. Use of prone positioning in Nonintubated patients with COVID-19 and hypoxemic acute respiratory failure. JAMA 2020. doi:10.1001/jama.2020.8255. [Epub ahead of print: 15 May 2020].

7 Sartini C, Tresoldi M, Scarpellini P, et al. Respiratory parameters in patients with COVID-19 after using noninvasive ventilation in the prone position outside the intensive care unit. JAMA 2020. doi:10.1001/jama.2020.7861. [Epub ahead of print: 15 May 2020].

8 Coppo A, Bellani G, Winterton D, et al. Feasibility and physiological effects of prone positioning in non-intubated patients with acute respiratory failure due to COVID-19 (PRON-COVID): a prospective cohort study. Lancet Respir Med 2020;8:765-74.

9 Rice TW, Wheeler AP, Bernard GR, et al. Comparison of the SpO2/ $\mathrm{FIO} 2$ ratio and the $\mathrm{PaO} 2 / \mathrm{FIO} 2$ ratio in patients with acute lung injury or ARDS. Chest 2007;132:410-7.

10 Roca O, Messika J, Caralt B, et al. Predicting success of high-flow nasal cannula in pneumonia patients with hypoxemic respiratory failure: the utility of the roX index. J Crit Care 2016;35:200-5.

11 Murray JF, Matthay MA, Luce JM, et al. An expanded definition of the adult respiratory distress syndrome. Am Rev Respir Dis 1988;138:720-3. 